\title{
PENGARUH MODEL GUIDED DISCOVERY LEARNING TERHADAP KEMAMPUAN BERPIKIR KRITIS ELEMENTARY CLARIFICATION (MEMBERIKAN PENJELASAN SEDERHANA)
}

\author{
Dede Yuni ${ }^{1)}$, Warsono ${ }^{2)}$, Ruhana Afifi ${ }^{3)}$ \\ ${ }^{1}$ Prodi Pendidikan Biologi, FKIP Universitas Galuh Ciamis \\ Email: dedeyuni729@yahoo.com \\ ${ }^{2}$ Prodi Pendidikan Biologi, FKIP Universitas Galuh Ciamis \\ Email: aasono09@gmail.com \\ ${ }^{3}$ Prodi Pendidikan Biologi, FKIP Universitas Galuh Ciamis \\ Email: ruhanaafifi@yahoo.com
}

APA Citation: Yuni, D., Warsono, \& Afifi, R. (2019). Pengaruh Model Guided Discovery Learning Terhadap Kemampuan Berpikir Kritis Elementary Clarification (Memberikan Penjelasan Sederhana). Quagga: Jurnal Pendidikan dan Biologi, 11(2), 88-92. doi: 10.25134/quagga.v11i2.1919.

Received: 29-07-2019

Accepted: $30-07-2019$

Published: 30-07-2019

Abstrak: Penelitian ini bertujuan untuk mengetahui pengaruh model Guided Discovery Learning (GDL) terhadap kemampuan berpikir kritis elementary clarification (memberikan penjelasan sederhana) siswa. Metode yang digunakan dalam penelitian ini adalah metode quasi eksperiment yang memberikan satu perlakuan terhadap subjek yang sama berupa penggunaan model pembelajaran GDL pada kelas eksperimen. Populasi dari penelitian ini adalah seluruh siswa kelas $X$ MIA SMAN 1 Baregbeg dengan pengambilan sampel menggunakan teknik purposive sampling. Adapun sampel yang terpilih adalah kelas X MIA 1 sebagai kelas eksperimen. Instrumen yang digunakan adalah instrumen tes kemampuan berpikir kritis yang terdiri dari 10 soal dengan pokok bahasan ekosistem. Hasil penelitian ini disimpulkanbahwa terdapat pengaruh model GDL terhadap kemampuan berpikir kritis elementary elarification (memberikan penjelasan sederhana) siswa.

Kata Kunci : guided discovery learning, berpikir kritis.

Abstract: This study aims to determine the effect of Guided Discovery Learning (GDL) models on critical thinking skills in elementary clarification (providing simple explanations) of students. The method used in this study is a quasi-experimental method that gives one treatment to the same subject in the form of using the GDL learning model in the experimental class. The population of this study was all students of class X MIA SMAN 1 Baregbeg with sampling using purposive sampling technique. The sample chosen was class X MIA 1 as an experimental class. The instrument used is a critical thinking ability test instrument consisting of 10 questions with the subject matter of the ecosystem. The results of this study concluded that there was an influence of the GDL model on elementary elarification (critical explanation) students' thinking ability.

Keywords: guided discovery learning, critical thinking.

\section{PENDAHULUAN}

Pembelajaran merupakan suatu proses yang dibangun oleh guru untuk mengembangkan kemampuan berpikir siswa, serta meningkatkan kemampuan mengkonstruksi pengetahuan baru sebagai upaya untuk menguasai konsep materi pelajaran. Sebagaimana yang tertuang dalam Peraturan Menteri Pendidikan Nasional (Permendiknas) No. 23 tahun 2006, kemampuan berpikir yang perlu dikembangkan dalam pembelajaran salah satunya adalah kemampuan berpikir kritis (Depdiknas, 2006). Berpikir kritis merupakan bagian dari cara berpikir yang secara mendalam terkait masalah-masalah dan hal-hal yang berbeda dalam jangkauan pengalaman seseorang. Oleh sebab itu berpikir kritis penting untuk dikembangkan dalam proses pembelajaran sebagai bekal untuk menghadapi permasalahan dalam kehidupan bermasyarakat.

Pada studi pendahulan peneliti melakukan wawancara dengan guru mata pelajaran biologi di SMAN 1 Baregbeg. Hasil wawancara dengan guru pelajaran biologi diperoleh fakta bahwa pembelajaran masih berpusat pada guru (teacher 
centered) dengan metode ceramah dalam menyampaikan materi ekosistem kepada siswa. Menurut pengakuan guru, siswa yang aktif hanya sekitar $10 \%$ saja dan hanya siswa tertentu saja yang aktif dalam pembelajaran. Berdasarkan observasi yang dilakukan pada hari selasa tanggal 25 Februari 2019 dengan memberikan pembagian angket yang dilakukan terhadap siswa SMAN 1 Baregbeg di satu kelas yaitu kelas X MIA 1 dengan jumlah keseluruhan 23 responden menunjukkan bahwa keterampilan berpikir kritis siswa masih dalam kategori rendah dimana pada indikator memberikan penjelasan sederhana (elementary clarification) yang meliputi: pertama memfokuskan pertanyaan didapat persentase $15 \%$, kedua menganalisis argumen didapat persentase $10 \%$, ketiga bertanya dan menjawab pertanyaan yang menantang di kelas X MIA 1 persentase $8 \%$. Rendahnya tingkat berpikir kritis siswa yang telah diuraikan disebabkan karena selama ini siswa hanya mendengarkan apa yang disampaikan oleh guru sehingga pembelajaran tidak berjalan dengan baik, karena siswa menganggap cara penyampaian yang diberikan oleh guru dirasa membosankan, sehingga siswa lebih asik mengobrol dengan teman sebangkunya, memainkan hand phone, dan mengerjakan tugas mata pelajaran lan.

Berdasarkan kondisi tersebut, maka pengembangan kemampuan berpikir kritis dalam pembelajaran perlu dioptimalkan dengan menerapkan model pembelajaran yang tepat dan inovatif, sehingga proses pembelajaran berlangsung optimal dan mampu mengembangkan kemampuan berpikir kritis siswa. Salah satunya adalah dengan menerapkan model Guided Discovery Learning (GDL).

GDLmerupakan sistem dua arahdimana proses pembelajarannya melibatkan siswa dan guru. Siswa melakukan penemuan (discovery) dan guru berperan dalam memberikan bimbingan (guided) dengan menganalisis kesulitan dalam memecahkan masalah yang dihadapi siswa (Satyawati, 2011). GDL dapat melatih kemampuan berpikir tingkat tinggi salah satunya adalah berpikir kritis.

Berpikir kritis merupakan kemampuan yang sangat diperlukan pada zaman sekarang. Selain itu berpikir kritis juga memiliki manfaat dalam jangka panjang, mendukung siswa dalam mengatur keterampilan belajar mereka, dan kemudian memberdayakan individu untuk berkonstruksi secara kreatif pada profesi yang mereka pilih (Sulistiani \& Masrukan, 2016). Berpikir kritis adalah sebuah proses sistematis yang terarah yang menjelaskan bahwa perilaku siswa terdiri dari dua dimensi yaitu: (a) perilaku yang berkaitan dengan materi pelajaran, dan (b) perilaku yang berkaitan dengan mental anak Zohar, et al. (dalam Rusyana 2014: 109).

Beberapa hasil penelitian yang telah dilakukan mengenai GDLhasilnya menunjukkan bahwa model $G D L$ berpengaruh terhadap kemampuan pemahaman dan hasil belajar siswa pada mata pelajaran Matematika sub materi Operasi Aljabar (Harianti, 2018). Adapun penelitian lain yang dilakukan bahwa dengan menggunakan model GDL pada mata pelajaran Fisika berpengaruh terhadap aktivitas belajar siswa disertai LKS berbasis multi representasi (Susiana, et al. 2017). Sementara itu penelitian Pengaruh Model GDL Terhadap Hasil Belajar Biologi di SMA Negeri 2 Sukorharjo Tahun Pelajaran 2013/2014 (Ulumi et al. 2015).

Penelitian GDL terhadap kemampuan berpikir kritis belum dilakukan pada mata pelajaran biologi, oleh karena itu maka penting untuk melakukan penelitian yang berjudul "Pengaruh Model GDL Terhadap Kemampuan Berpikir Kritis Elementary Clarification (Memberikan Penjelasan Sederhana) Siswa SMA".

Rumusan masalah yang didapat dari latar belakang di atas yaitu: "Apakah terdapat pengaruh model GDL terhadap kemampuan berpikir kritiselementary clarification (memberikan penjelasan sederhana) siswa?"

Tujuan yang ingin dicapai dalam penelitian ini adalah untuk mengetahui pengaruh model GDL terhadap kemampuan berpikir kritis elementary clarification (memberikan penjelasan sederhana) siswa.

\section{METODE PENELITIAN}

Metode penelitian ini termasuk jenis penelitian Quasi Eksperiment (Sugiyono 2017: 77). Variabel penelitian terdiri atas dua variabel yaitu variabel terikat $(\mathrm{X})$ meliputi pembelajaran $G D L$ dan variabel bebas (Y) meliputi peningkatan kemampuan berpikir kritis elementary clarification (memberikan penjelasan sederhana) siswa setelah menggunakan model pembelajaran $G D L$. Populasi pada penelitian ini adalah seluruh kelas $\mathrm{X}$ (sepuluh) MIA SMA Negeri 1 Baregbeg Ciamis, sebanyak 2 kelas dengan jumlah siswa 45 siswa. Desain yang dilakukan dalam penelitian ini adalah One group pretest-posttest. Peneliti menggunakan 1 kelas eksperimen tanpa kelas kontrol. Desain ini dapat digambarkan seperti pada Gambar1. 
Quagga: Jurnal Pendidikan dan Biologi

Volume 11, Nomor 2, Juli 2019

telah dilakukan dengan mengambil taraf signifikan $\alpha=0,01$ menyatakan bahwa $X_{\text {hitung }}^{2}<$ $X_{\text {tabel }(\alpha=1 \%)}^{2}$ yaitu $6,47<9,2$ hal ini menunjukkan bahwa data yang diperoleh berdistribusi normal, selanjutnya data dianalisis dengan menggunakan uji Z. Hasil ringkasan uji hipotesis dapat dilihat pada Tabel 2.

Tabel 2. Hasil Uji Z penelitian ini dengan menggunakan tes tertulis berupa essay. Instrumen pengambilan data menggunakan tes tertulis berupa uraian yang disesuaikan dengan materi dan indikator kemampuan berpikir kritis Elementry Clarification (Memberikan Penjelasan Sederhana). Bentuk tes yang diberikan pada tes awal sama dengan yang diberikan pada tes akhir. Tes awal bertujuan ini bertujuan untuk mengukur kemampuan awal, sedangkan tes akhir bertujuan untuk mengukur kemajuan dan tingkat hasil belajar kemampuan berpikir kritis siswa setelah dilakukan pembelajaran menggunakan model GDL. Teknik analisis data yang digunakan adalah statistika deskriptif, uji prasyarat dengan menggunakan uji normalitas, dan uji hipotesis dengan menggunakan uji Z.

\section{HASIL DAN PEMBAHASAN}

Berdasarkan data hasil penelitian yang berjudul Pengaruh Model Guided Discovery Learning Terhadap Kemampuan Berpikir Kritis Elementary Clarification (Memberikan Penjelasan Sederhana) Siswa SMA. Data ratarata nilai pretest posttest dan $\mathrm{N}$-gain dapat dilihat pada Tabel 1.

Tabel 1. Hasil Rata-rata Nilai Pretest, Posttest dan N-Gain

\begin{tabular}{ccccc}
\hline Kelas & Jumlah & $\begin{array}{c}\text { Rata- } \\
\text { rata } \\
\text { Pretest }\end{array}$ & $\begin{array}{c}\text { Rata- } \\
\text { rata } \\
\text { Posttest }\end{array}$ & $\begin{array}{c}\text { N- } \\
\text { gain }\end{array}$ \\
\hline Eksperimen & 23 & 36,52 & 74,35 & 58,26 \\
\hline
\end{tabular}

Tabel 1 menyatakan rata-rata hasil $\mathrm{N}$-gain yaitu 58,26. Selain itu berdasarkan rata-rata skor pretest dan posttest, tingkat pengaruh awal siswa yaitu sebesar 36,52 sedangkan pengukuran hasil akhir siswa sebesar74,35. Hal ini menunjukkan adanya peningkatan kemampuan berpikir kritis elementary clarification (memberikan penjelasan sederhana) siswadengan menggunakan model $G D L$.

Nilai $N$-gain dari hasil perhitungan statistika deskriptif kemudian dilakukan uji normlalitas untuk mengetahui distribusi data tersebut normal atau tidak. Berdasarkan hasil uji normalitas yang

\begin{tabular}{llll}
\hline & $\mathbf{Z}_{\text {hit ung }}$ & $\begin{array}{l}\mathbf{Z}_{\text {tabel }} \\
(\mathbf{0 , 0 5 )}\end{array}$ & Keterangan \\
\hline$N$-gain & $-3,49$ & 1,96 & $\mathrm{H}_{0}$ ditolak \\
\hline
\end{tabular}

Berdasarkan Tabel 4.2 menunjukkan bahwa hasil uji hipotesis dengan mengambil taraf signifikasi $\alpha=0,05$ dapat diketahui bahwa nilai $Z_{\text {hitung }}>Z_{\text {tabel }}$ yaitu $-3,49>1,96$, maka hipotesis ditolak. Artinya terdapat pengaruh model $G D L$ terhadap kemampuan berpikir kritis elementary clarification (memberikan penjelasan sederhana) siswa SMA. Berdasarkan hasil penelitian diperoleh data $N$-gain disajikan pada Tabel 3.

Tabel 3. Hasil Uji N-gain (Uji Tingkat Pengaruh)

\begin{tabular}{ccc}
\hline Indeks Gain & $\boldsymbol{N}$-Gain $(\boldsymbol{\%})$ & Kriteria \\
\hline 0,58 & 58,26 & Sedang \\
\hline
\end{tabular}

Berdasarkan Tabel 4.3 dapat dilihat kriteria $N$-gain sebesar 58,26 (sedang), hal ini menunjukkan adanya peningkatan kemampuan berpikir kritis elementary clarification (memberikan penjelasan sederhana) dengan menggunakan model pembelajaran GDL.

\section{Pembahasan}

Berdasarkan perhitungan uji $\mathrm{Z}$ dapat diketahui bahwa $Z_{\text {hitung }}>Z_{\text {tabel }}$ yang berarti terdapat pengaruh model $G D L$ terhadap kemampuan berpikir kritis elementary clarification (memberikan penjelasan sederhana) siswa SMA.

Berdasarkan hasil data dan pengujian hipotesis yang telah diuraikan di atas, penerapan model $G D L$ terhadap kemampuan berpikir kritis elementary clarification (memberikan pnjelasan sederhana) mencapai $58,26 \%$ dengan kriteria sedang. Kemungkinan model $G D L$ berpengaruh karena dengan menerapkan model GDL ini siswa dapat lebih berpikir kritis dalam pembelajaran, siswa dapat berperan aktif juga dapat menjawab permasalahan yang ada dalam kehidupan nyata.

Suasana pembelajaran yang dirasakan peneliti ketika melaksanakan penelitian dengan menggunakan model $G D L$, siswa antusias dalam melaksanakan pembelajaran, siswa lebih aktif 
ketika melakukan diskusi dengan kelompoknya. Siwa lebih mendengarkan apa yang disampaikan oleh guru, berbeda halnya dengan model pembelajaran konvensional yang menekankan kepada guru sehingga siswa kurang berperan aktif dalam pembelajaran.

Ketika melaksanakan pembelajaran pada sintaks kedua yaitu dalam merumuskan masalah di sintaks inilah siswa lebih mengembangkan kemampuan berpikirnya, sehingga siswa lebih berperan aktif dalam mecari permasalahan yang akan mereka rumuskan, siswa lebih bekerja sama dalam berdiskusi dengan kelompoknya sehingga mereka lebih saling berkomunikasi satu dengan yang lainnya.

Pada sintaks ketiga yaitu merumuskan hipoteis atau membuat dugaan sementara, disinilah siswa saling berdiskusi tentang apa yang dapat mereka jadikan sebagai hipotesis, ada kelompok siswa yang menjawab bahwa hipotesis yang mereka rumuskan adalah terjadinya interaksi, jawaban itu mereka yakini karena mereka melihat gambar yang ditampilkan oleh guru, di dalam gambar tersebut menampilkan interakasi antara ikan hiu dengan ikan ramora, dan juga interaksi antara komponen biotik dengan abiotik.

Sintaks keempat yaitu mengumpulkan data pada sintaks ini guru mengajak siswa keluar langsung ke lapangan untuk membuktikan hipotesis yang mereka ajukan. Di sintaks inilah siswa antusias dalam membuktikan jawaban yang telah mereka ajukan karena pada pembelajaran sebelumnya siswa tidak diajak langsung keluar kelas dalam melakukan pembelajaran. Dengan model GDL ini yang mengajak langsung siswa ke lapangan membuat rasa ingin tahu siswa semakin besar dan juga rasa penasaran dengan hipotesis yang siswa ajukan telah siswa pecahkan, sehingga siswa menjadi yakin akan hipoteis yang mereka ajukan itu benar bahwa dilingkungan terjadi adanya interaksi antara komponen biotik dengan komponen biotik, maupun komponen biotik dengan komponen abiotik.

Sintaks kelima menguji hipotesis pada sintaks ini siswa menjawab persoalan sesuai dengan data yang mereka peroleh, disinilah kelompok siswa lebih berperan aktif dalam mencari data yang sesuai dengan apa yang telah dijadikan sebagai hipotesis. Kelompoknya yang satu berpencar dengan kelompok yang lainnya, ada yang meneliti di kebun sekolah, di kolam, dan juga di parit/selokan sehingga kelompok yang satu bertukaran tempat dengan kelompok yang lainnya setelah mereka mendapatkan data.

Sintaks keenam membuat kesimpulan, pada sintaks ini siswa diminta untuk menarik kesimpulan sesuai dengan data yang mereka dapatkan. Ada beberapa kelompok yang ingin menyampaikan data hasil kesimpulannya, mereka saling berebutan ketika peneliti menanyakan kelompok yang mana yang akan terlebih dahulu menyampaikan kesimpulan yang mereka dapatkan. Karena banyaknya data yang kelompok siswa dapatkan sehingga mereka berlomba-lomba ingin menyampaikan hasil penelitiannya terlebih dahulu.

Selain suasana pembelajaran yang dirasakan peneliti ketika melaksanakan model GDL di dalam maupun di luar kelas yang berdampak baik terdapat beberapa keunggulan dari model $G D L$ itu sendiri yangdiantaranya: Proses $G D L$ lebih menguntungkan untuk meningkatkan penemuan konsep siswa. Karena dalam penemuan terbimbing ini guru bertujuan untuk membantu siswa dalam memahami tujuan dan prosedur kegiatan pembelajaran.Model GDL lebih efektif dalam pembelajaran, karena model ini membantu peserta didik bertemu dengan dua kriteria penting dalam pembelajaran aktif, yaitu membangun pengetahuan untuk membuat pengertian dan informasi baru sampai ditemukan pengetahuan yang tepat (Tanjung \& Aminah, 2015). Menimbulkan rasa senang pada siswa, karena membangkitkan keingintahuan siswa, memotivasi siswa untuk bekerja terus sampai menemukan jawaban. GDL bisa dilaksanakan dengan baik maka akan menghasilkan pemahaman konsep yang mendalam pada siswa dan menghasilkan penyimpanan jangka panjang yang baik, serta mendorong siswa berpikir kritis (Lestari, 2015).

\section{SIMPULAN}

Berdasarkan data hasil penelitian dan hasil analisis data bahwa terdapat pengaruh model $G D L$ terhadap kemampuan berpikir kritis elementary clarification (memberikan penjelasan sederhana) siswa SMA.

\section{Saran}

1. Bagi guru, model pembelajaran $G D L$ dapat dijadikan alternatif model pembelajaran di sekolah untuk meningkatkan kemampuan berpikir kritis siswa. Agar pelaksanaan pembelajaran lebih efektif, maka perlu adanya jadwal yang teratur agar pembelajaran $G D L$ dapat tercapai. 
2. Bagi siswa, model pembelajaran $G D L$ dapat dijadikan sarana untuk memacu kemampuan berpikir kritis serta mampu mencari solusi dalam memecahkan permasalahan.

3. Bagi peneliti lain, diharapkan dapat melakukan penelitian lebih lanjut berkaitan dengan model pembelajaran $G D L$, dalam cakupan materi lain sehingga kemampuan berpikir kritis siswa dapat diamati lebih teliti.

\section{REFERENSI}

Harianti, F. (2018). "Pengaruh Model Guided Discovery Learning Terhdap Kemampuan dan Hasil Belajar Siswa Materi Operasi Aljabar Kelas VII SMP". MUST: J. of Mathematics Education, Science and Technology. 3(1):82-91.

Rusyana, A. (2014). Keterampilan Berpikir. Yogyakarta: Ombak

Satyawati. (2011). Pengaruh Model Pembelajaran Penemuan Terbimbing Berbasis LKS terhadap Hasil Belajar Matematika Siswa Ditinjau dari Kecerdasan Logis Matematis pada Siswa Kelas X SMAN 1 Bangli. J. Penelitian Pasca sarjana Undiks, 2(2): 1-17.

Sugiyono. (2017). Metode Penelitian Kuantitatif, dan $R \& D$. Bandung: Alfabeta

Sulistiani dan Masrukan. (2016). "Pentingnya Berpikir Kritis dalam Pembelajaran Matematika untuk Menghadapi Tantangan MEA". J. Seminar Nasional Matematika $X$ Universitas Negeri Semarang. 605-612

Susiana, Mahardika, I.K. dan Bachtiar, R.W. (2017). "Pengaruh Model Pembelajaran Guided Discovery Learning disertai LKS Berbasis Multirepresentasi Terhadap Kemampuan Representasi Verbal, dan Gambar (VG) Siswa dalam Pembelajaran Fisika". J. Pembelajaran Fisika, 6(1): 16-23

Tanjung dan Aminah. 2015. Pengaruh Model Pembelajaran Guided Discovery Learning Menggunakan Media Peta Pikiran terhadap Hasil Belajar Siswa pada Materi Pokok Listrik Dinamis di Kelas X Semester Genap SMA Cerdas Murni Tembung T.P 2014/2015. J. Ikatan Alumni Fisika Universitas Negeri Medan, 7(1): 1-4.
Ulumi, D.F., Maridi. dan Rianto, Y. (2015). "Pengaruh Model Pembelajaran Guided Discovery Learning Terhadap Hasil Belajar Biologi di SMA Negeri 2 Sukoharjo Tahun Pelajaran 2013/2014". J. Pendidikan Biologi, 7(2): 68-79. 